\title{
O Uso de Recursos Lúdicos Para o Ensino de Processos em Engenharia de Software
}

\author{
Ronney Moreira de Castro ${ }^{1,2}$, Gleison dos Santos Souza ${ }^{2}$ \\ ${ }^{1}$ Faculdade Metodista Granbery - Juiz de Fora (FMG) \\ Rua Batista de Oliveira, 1145 - Granbery - Juiz de Fora - MG - Brasil \\ ${ }^{2}$ Programa de Pós-Graduação em Informática (PPGI) \\ Universidade Federal do Estado do Rio de Janeiro(UNIRIO) \\ Av. Pasteur, 456 -Urca -Rio de Janeiro -RJ - Brasil \\ ronney.castro@granbery.edu.br, gleison.santos@uniriotec.br
}

\begin{abstract}
Teachers and students faces considerable difficulty teaching the use of processes in Software Engineering courses because most of adopted methodologies are based on expository classes with low efficiency. In this article a different approach is presented, which uses ludic resources to aid the teaching of processes, in order to improve students knowledge absorption and consequently bring to practice knowledge only seen in theory.

Resumo. Docentes e alunos têm enfrentado grande dificuldade no que se refere à abordagem de ensino-aprendizagem do uso de processos na disciplina de Engenharia de Software, pois a maioria das metodologias adotadas atualmente se baseiam em aulas expositivas com pouca eficiência. Neste artigo é apresentada uma abordagem diferente, que utiliza recursos lúdicos para o auxílio ao ensino de processos, com o objetivo de melhorar a absorção de conhecimento pelos alunos e, consequentemente, trazer para a prática conhecimentos somente vistos na teoria
\end{abstract}

\section{Introdução}

A Engenharia de Software (ES) é parte do currículo de muitos cursos superiores de computação. Ela é ensinada geralmente em uma ou mais disciplinas nos cursos de Sistemas de Informação e Ciência da Computação e, muitas vezes, o aprofundamento em seus conhecimentos é feito em nível de Pós-Graduação. A ES está mais diretamente relacionada ao desenvolvimento de software propriamente dito, englobando conteúdos de qualidade, processos de desenvolvimento, técnicas para gerenciamento de projetos, metodologias, entre outros. Cada um desses conteúdos possui diferentes tipos de problemas com características específicas de seu contexto.

Os métodos tradicionais de ensino de ES ainda estão excessivamente centrados no professor, focados na aplicação de teorias para os alunos e, muitas vezes, a parte prática é feita de forma simples utilizando algumas ferramentas em laboratórios ou exercícios em da sala de aula. Isso leva os alunos a uma falta de oportunidade de aplicação prática do conteúdo, podendo gerar desmotivação pela disciplina. Uma forma de melhorar a situação descrita é o uso de métodos alternativos para o ensino da disciplina, tais como estudos de caso, atividades envolvendo projetos de empresas, uso de jogos (tabuleiro, cartas, eletrônicos), aplicação de dinâmicas de grupo, uso de simuladores. Já existem pesquisas como as citadas em Wangenheim [2012], cujo 
objetivo é alcançar uma melhoria no ensino de ES. Em sua maioria estão relacionadas ao uso específico de jogos, como, por exemplo, jogos computacionais (projetados para serem jogados através de um software) que envolvem conteúdos da área [FERNANDES e WERNER, 2009].

Este artigo aborda uma forma lúdica de ensinar o que são processos de software fazendo analogia ao uso destes dentro da ES. A Seção 2 aborda metodologias de ensino e aprendizagem, a Seção 3 discorre sobre processos de software, a Seção 4 mostra a dinâmica desenvolvida e sua aplicação, a Seção 5 apresenta os resultados obtidos por este trabalho e, por fim, as conclusões são apresentadas na Seção 6.

\section{Evolução das Metodologias de Ensino}

A compreensão do funcionamento da mente humana foi um dos principais objetivos e temas de pesquisa de Jean Piaget. Ele buscava compreender, de forma analítica, todas as fases do desenvolvimento humano e suas características psicológicas e mentais [PIAGET, 2003]. A Psicologia da Aprendizagem possui uma série de teorias, dentre as quais, este artigo apresenta três das mais conhecidas: teoria comportamental, teoria cognitivista e teoria construtivista.

\section{1 - Psicologia Comportamental}

Segundo Baum [1999], a teoria teve início em 1913 por John B. Watson, na qual defendia que a psicologia não deveria estudar os processos internos da mente, mas do comportamento, que era visível. Nesta época a investigação se baseou na observação do comportamento mediante a situação e limites impostos. Sua crença o levou a acreditar que seria possível prever e controlar a conduta humana.

A base foi no estudo e nas teorias do russo Ivan Pavlov sobre condicionamento, como observar aos estímulos gerados ao ver, por exemplo: um cachorro salivar não somente ao ver comida, mas também com o som, gesto ou sinal de chegada da refeição. Qualquer alteração que resulta no estímulo do meio-ambiente pode provocar modificação no comportamento. Nem toda conduta pode ser detectada seguindo esta teoria. Eduard C. Tolman propõe o Neobehaviorismo Mediacional. Nessa teoria o organismo trabalha como mediador entre o estímulo e a resposta, ou seja, ele atravessa etapas que Tolman denominava de variáveis intervenientes - elos conectivos entre estímulos e respostas, estas sim consideradas ações internas [BAUM, 1999] [CATÂNIA, 1999].

\section{2 - Psicologia Cognitiva}

Segundo Matlin [2004], a psicologia cognitiva é uma área da psicologia que pesquisa as variadas formas de como o ser humano aprende, pensa, percebe e a forma de representação da realidade. Esse ramo abrange também como principais focos de pesquisa, a percepção, o pensamento e a memória, de forma a explicar como o indivíduo compreende o mundo e faz uso do conhecimento adquirido para várias funções cognitivas, tais como falar, raciocinar, memorizar e solucionar problemas.

O processo de transformação das estruturas cognitivas ocorre através da assimilação e acomodação. A assimilação se baseia na interpretação de eventos das estruturas cognitivas existentes. Pelo contrário, a acomodação se baseia na modificação desta estrutura com o objetivo de compreensão do meio. 


\section{3 - Psicologia Construtivista}

A ideia de investigar o surgimento do conhecimento e, como nasce à necessidade da pessoa buscar o mesmo, fez com que Jean Piaget se propusesse a estudar esse fenômeno e entender, nas diversas fases do desenvolvimento do ser humano, como surge o conhecimento e como ele se desenvolve. Algo extremamente interessante observado por Piaget [2003] foi que qualquer pessoa, para poder tentar realizar uma tarefa ou buscar o conhecimento a envolvendo, tem a necessidade de ter pelo menos visto alguém desempenhá-la, ou seja, precisa de um contato inicial, mesmo que de forma bem sucinta para que, a partir daí, seja despertado nessa pessoa a necessidade de aprender.

\subsection{Aprendizagem}

$\mathrm{O}$ ato de adquirir conhecimento, informação e habilidades através de ensino, estudo ou até vivência no dia a dia é denominado aprendizagem. De acordo com Tapajós [2008], no âmbito pedagógico, a aprendizagem é abordada de diversas formas onde cada uma possui sua peculiaridade.

A aprendizagem receptiva, onde o individuo é capaz de receber uma instrução e compreendê-la, é possível reproduzir o que lhe foi passado, mas é incapaz de descobrir algo; a aprendizagem por descoberta, onde a pessoa tem que trabalhar para poder conseguir aprender algo, nada é fornecido facilmente. Outra aprendizagem que merece destaque é a repetitiva, na qual existe a memorização do conteúdo, embora a compreensão inicial seja um pouco confusa. Por último, a aprendizagem significativa onde à pessoa consegue relacionar os seus conhecimentos prévios com novas informações passadas [TAPAJOS, 2008].

\section{O Ensino da Definição de Processo}

Para Filho [2009], processo é uma sequência de etapas que deverão ser seguidas a fim de se atingir um objetivo e agrupa uma série de ferramentas e técnicas. Scheer et al. [2006] relata que a ideia de analisar e melhorar os processos veio da indústria da manufatura e foi difundida para outros setores. Pressman [2011] define processos como um conjunto de atividades, ações e tarefas realizadas na criação de algum produto de trabalho. Gerenciá-los implica em uma verificação detalhada de atividades importantes e dos recursos da organização, tais como mercado onde está inserida, suas atividades, pessoas, entre outros.

Pela afirmação de vários autores compreende-se que processos são atividades organizadas e utilizadas de forma adequada para obtenção de um determinado resultado a um alto nível qualitativo. O seu uso está sendo difundido nas empresas que estão em busca de uma melhor qualidade em seus produtos [DAVIS, 2008]. Jones [2010] relata que estudos atuais mostram que as empresas estão procurando compreender os processos que possuem, o que pode afetar sua capacidade de planejar, justificar e implementar as alterações que impactarão nos mesmos, deixando-os mais coerentes com as necessidades e fornecendo mais do que o necessário para uma empresa conquistar um produto bem feito. Segundo o autor, se eles forem seguidos de forma correta irão prevenir as ocorrências de falhas que podem afetar o produto final. 


\subsection{Aplicações de Processos}

Um dos fatores que impulsionaram o constante crescimento do uso de sistemas nas empresas é a competitividade que eles oferecem. Com isso, houve também um grande crescimento na construção dos softwares, produzidos de forma corriqueira e sem nenhuma qualidade aparente, caso conhecido na literatura como "Crise do Software" [WAZLAWICK, 2013].

Fernandes e Teixeira [2011] descrevem o processo de software fazendo um paralelo entre as operações de manufatura. Da mesma forma que se decompõe as etapas de operações de manufatura, o processo de software pode ser dividido em várias partes. Júnior [2002] descreve procedimentos, subprocessos, como a identificação das funções, a complexidade e classificação de um ponto, representando a funcionalidade provida ao usuário, para atender seus requisitos internos e externos em relação aos dados.

\subsection{Abordando as Definições em Sala de Aula}

De acordo com Behrens [1999], existem dois métodos utilizados para o ensino: um é focado no professor e o outro no aluno. De fato, observa-se uma maior utilização nos dias atuais da metodologia voltada para aulas expositivas, onde o professor fala e os alunos somente ouvem. Nesse tipo de aula não se tem grande aproveitamento pelos alunos, pois estes se dispersam nos primeiros minutos de aula.

A disciplina Qualidade de Software (QS) é de grande relevância para formação dos conhecimentos de ES e, a maior parte de seu conteúdo, é lecionada pelos docentes de forma expositiva, teórica e bastante abstrata e, com isso, acaba sendo menos eficiente, pois ativa somente a audição do aluno [ALBUQUERQUE, 2009]. Para entendimento do conteúdo de QS, é necessário o conhecimento de processos, que é a base para um software com qualidade. No entanto, lecionar processos, assim como outros tópicos da disciplina, envolve um conteúdo muito teórico sendo considerado um desafio para os docentes dos cursos de graduação nos dias atuais.

Para Albuquerque [2009], o ensino do que é processo inicia-se pela conceituação, para que os alunos entendam sua função dentro do contexto em que se encontra. $\mathrm{O}$ professor utiliza geralmente slides para a transmissão do conhecimento. Em paralelo, para complementar o entendimento, são buscadas informações em outras fontes, como em artigos. Durante o aprendizado são demostrados alguns exemplos de empresas que utilizam processos para melhoria da qualidade do produto final e, de forma paralela, é justificado o uso dos mesmos no cenário da ES. Em suma, ensinar processos no ambiente de graduação tem como principal objetivo fazer com que o aluno entenda a sua importância para a qualidade de um produto.

\section{O uso de uma Dinâmica de Grupo como Alternativa para Ensino de Processos}

A metodologia que mais se utiliza no processo de ensino e aprendizado da ES é a expositiva, onde o professor fala e os alunos escutam [WANGENHEIM, 2012]. A intenção deste trabalho é apresentar uma técnica alternativa de ensino, na qual os alunos tenham uma maior eficácia no aprendizado promovendo interação social, desafio, competição e, consequentemente, a recompensa, o que os mantêm mais ativos, auxiliando na aprendizagem.

A dinâmica construída consiste na elaboração de um boneco montado por partes. $\mathrm{O}$ objetivo é que os alunos produzam o mesmo utilizando a abordagem de processo. No 
decorrer da dinâmica são inseridas algumas variações cujo objetivo é demonstrar como o processo não é estático em uma organização, devendo sofrer melhorias constantes, de acordo com o que é observado durante seu uso. Os detalhes da dinâmica, assim como sua preparação, podem ser observados na Tabela 1 .

\section{Tabela 1. Detalhes e preparação para a dinâmica}

\begin{tabular}{|c|c|}
\hline Título & Criação do boneco para ensinar a abordagem de processos e sua utilização. \\
\hline Objetivo & $\begin{array}{l}\text { Mostrar que um processo desorganizado pode afetar a criação de um produto } \\
\text { e, que processos alinhados, podem ser bem melhores para as organizações. } \\
\text { Mostrar aos alunos, por analogia, que processo em software pode contribuir } \\
\text { positivamente para a geração de um produto final de melhor qualidade. }\end{array}$ \\
\hline Participantes & Grupos de cinco a seis alunos. \\
\hline Tempo & 50 a 100 minutos. \\
\hline $\begin{array}{l}\text { Material } \\
\text { utilizado }\end{array}$ & $\begin{array}{l}13 \text { cartões que conterão as partes do boneco, } 13 \text { envelopes de cartão, } \\
\text { tesouras, jornal, lápis ou caneta, fita adesiva e um quadro para fixação das } \\
\text { peças que serão montadas. }\end{array}$ \\
\hline Preparação & $\begin{array}{l}\text { Cada envelope deverá conter um cartão escrito com uma peça do boneco a } \\
\text { ser confeccionada: } 1^{\mathrm{a}} \text { peça: cabeça, } 2^{\mathrm{a}} \text { peça: orelha direita, } 3^{\mathrm{a}} \text { peça: orelha } \\
\text { esquerda, } 4^{\mathrm{a}} \text { peça: pescoço, } 5^{\mathrm{a}} \text { peça: corpo (tronco), } 6^{\mathrm{a}} \text { peça: braço direito, } 7^{\mathrm{a}} \\
\text { peça: braço esquerdo, } 8^{\mathrm{a}} \text { peça: mão direita, } 9^{\mathrm{a}} \text { peça: mão esquerda, } 10^{\mathrm{a}} \text { peça: } \\
\text { perna direita, } 11^{\mathrm{a}} \text { peça: perna esquerda, } 12^{\mathrm{a}} \text { peça: pé direito, } 13^{\mathrm{a}} \text { peça: pé } \\
\text { esquerdo. }\end{array}$ \\
\hline
\end{tabular}

Descrição: A dinâmica começa com o professor dividindo a turma em grupos de 5 a 6 pessoas, dispostas em lugares distintos na sala, de forma que um grupo não possa ver o que outro estará fazendo. Ele deve explicar a todos que será aplicada uma atividade que envolverá definições da disciplina ES, mais especificamente: O Uso de Processos para a Melhoria da Qualidade. É necessário também, embaralhar os cartões antes de distribuí-los aos participantes a cada fase. Logo após, deverá distribuir dois a três envelopes para cada grupo e solicitará aos participantes para não abri-los até que seja dada ordem. Será entregue, nesse momento, folhas de jornal e tesouras. O professor, então, informa aos alunos que eles devem construir com o material disponibilizado, o que está escrito nos cartões.

Aplicação: A dinâmica foi aplicada em turmas do $7^{\circ}$ e $8^{\circ}$ períodos do Curso de Bacharelado em Sistemas de Informação da Faculdade Metodista Granbery nos anos de 2014 e 2015. Em todas as aplicações foram feitas quatro etapas.

Na primeira etapa todas as equipes foram proibidas de se comunicar umas com as outras. O objetivo era de simular a dificuldade que se tem no processo de desenvolvimento de software, onde não existe comunicação com os envolvidos no processo, criando um ambiente nada colaborativo e completamente desorganizado.

O professor estipulou um prazo de 15 minutos para término da tarefa, simulando o tempo corrente para a criação de um produto em um ambiente real. Após o término desse prazo, foi solicitado que todas as equipes aguardassem para poder iniciar a montagem do produto final no quadro. As peças, uma a uma, foram fixadas com fita adesiva no quadro e, no fim, o produto obtido foi de qualidade muito baixa, sendo facilmente visualizado por todos. O objetivo da primeira etapa, que era simular uma produção independente, sem comunicação e padronização foi obtido com total ênfase, já que o produto criado foi um produto ruim, sem aceitação de todos e sem nenhuma 
padronização. A Figura 1 mostra os participantes durante a primeira fase da dinâmica e o boneco gerado nessa fase.
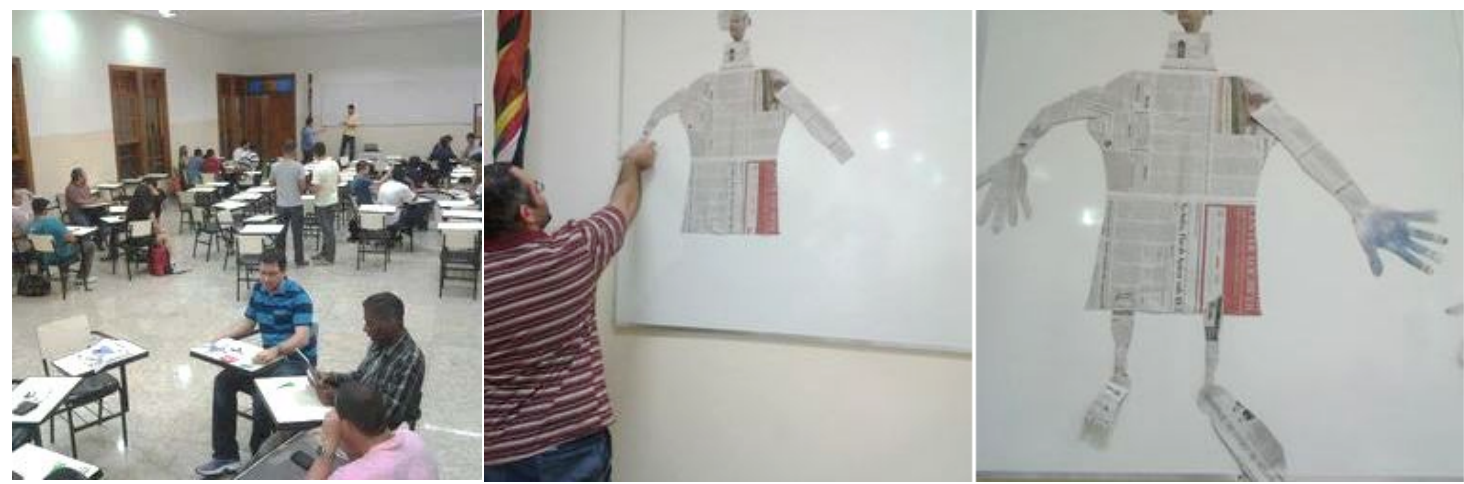

Figura 1 - Participantes e boneco gerado na primeira fase da dinâmica

$\mathrm{Na}$ etapa posterior foram eleitos líderes de equipes e somente estes estavam liberados para efetuar a comunicação com os demais líderes das outras equipes, simulando o papel de gerente de projetos. Esse, por sua vez, tinha como objetivo compreender as demandas, tentar alinhar sua equipe com as demais e, no final, produzir um produto de qualidade. Foi observado que as pessoas encontraram dificuldades por não haver documentação ou algo que as orientassem.

Isso demonstrou a importância de documentação para a realização de qualquer desenvolvimento de software, pois a padronização dos processos envolvidos é extremamente vital para o sucesso de um projeto que visa qualidade. A Figura 2 ilustra o boneco gerado na segunda fase.

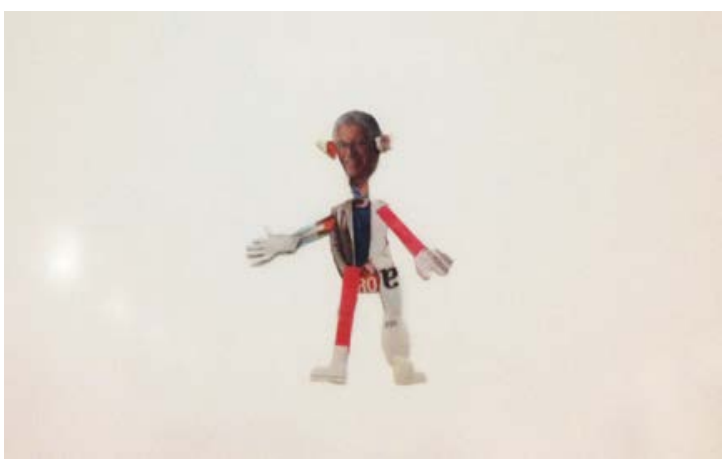

Figura 2 - Boneco gerado na segunda fase da dinâmica

$\mathrm{Na}$ terceira etapa, uma pessoa foi eleita como modelo. Essa por sua vez serviu como inspiração para as demais equipes e também simulou uma documentação, na qual os envolvidos poderiam observar e copiar as medidas. Com isso, observou-se uma melhoria da qualidade do produto final, já que as equipes de trabalho tinham algo em que se basear, análogo a uma documentação. A Figura 3 ilustra a utilização do modelo e o boneco que estava sendo gerado nessa fase. 


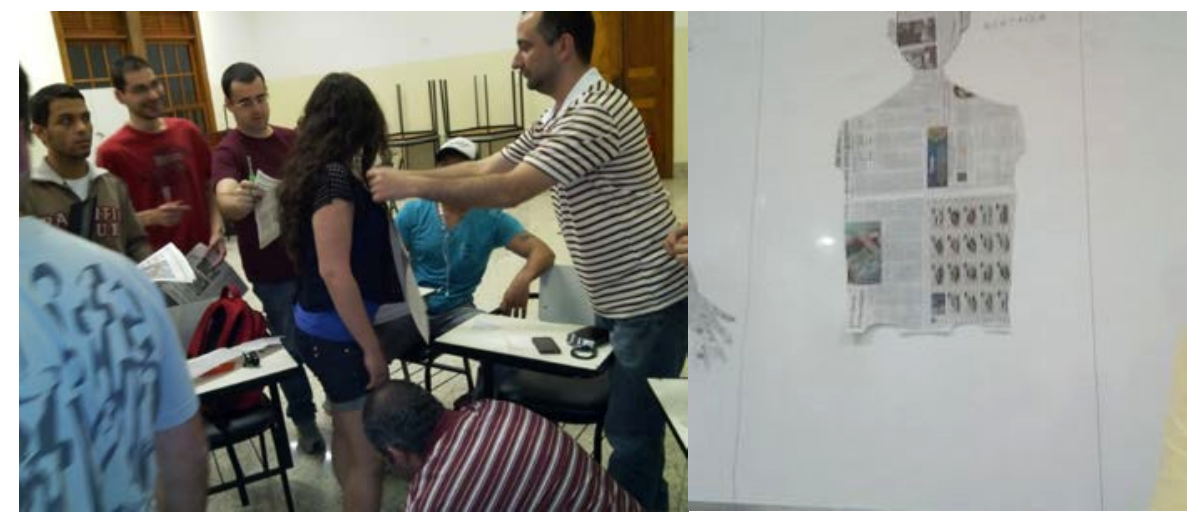

Figura 3 - Uso de um modelo e boneco sendo gerado na terceira fase da dinâmica

Nessa mesma fase foram eleitos também gerentes de projetos e de qualidade, com as tarefas de gerenciar e auditar o processo de todas as equipes, simulando uma forma bem similar à produção atual de um software no dia a dia. Ambos tinham o poder de aprovar ou até mesmo reprovar as demandas realizadas pelas equipes.

$\mathrm{Na}$ última etapa os participantes foram inseridos em um ambiente que era bem próximo da realidade, com seus gerentes, líderes e analistas de qualidade, todos desempenhando tarefas inerentes ao seu cargo e as equipes sempre envolvidas no processo de produção. No final, o produto construído, com o auxílio de padronização, sob uma supervisão de gerentes e guiados por analistas focando a qualidade, ficou muito melhor com relação as demais etapas anteriores, conforme ilustra a Figura 4.

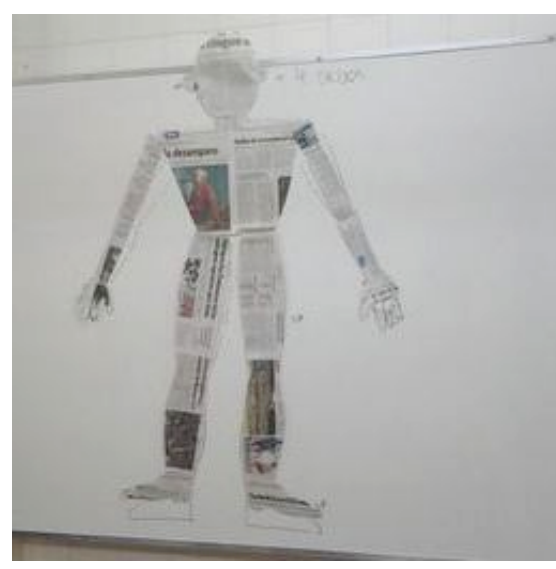

Figura 4 - Boneco gerado na última fase da dinâmica

\subsection{Abordagens utilizadas}

Segundo Wangenheim [2012], o uso de recursos lúdicos, como a dinâmica de grupo, por exemplo, favorece positivamente o processo de aprendizagem, pois mantém os alunos mais ativos.

Objetivando-se uma maior eficiência no processo de ensino e aprendizado, a dinâmica elaborada baseou-se na ideia central da psicologia cognitiva, que estuda a forma como o ser humano assimila as coisas que a realidade oferece. Os alunos foram convidados a aprender de maneira prática o que é um processo e fazer a analogia ao processo de desenvolvimento de software. Eles foram motivados a cada etapa e, à 
medida que o projeto se desenvolveu, foram assimilando a ideia de trabalho em equipe, gerência de requisitos, elaboração de documentação, além da importância do uso de processos na produção de software.

\section{Resultados}

Ao fim da dinâmica foi feita uma análise a partir do primeiro boneco até o quarto. Foi perceptível, através da visualização dos bonecos no quadro, a melhora no desenvolvimento do processo e, consequentemente, do produto. Foram acrescentadas várias definições entre as discussões para esta evolução. Os alunos puderam perceber que era necessário continuar evoluindo para obter um melhor produto. Através desta dinâmica foram observados diversos benefícios como: bem-estar, motivação, melhor aprendizado, aprender com o erro e a dificuldade em lidar com pessoas. Os alunos tiveram a chance de cometer erros e analisar o fracasso, dando oportunidade de vivenciar uma experiência próxima do mercado de trabalho e que, em geral, o ambiente acadêmico não possibilita.

Após a dinâmica, os participantes foram convidados a preencher um questionário com 25 afirmativas, cada uma delas com opções de notas: 0 (muito ruim), 1 (ruim), 2 (razoável), 3 (bom), 4 (muito bom) e 5 (excelente), para serem respondidas como feedback do trabalho realizado. A Tabela 2 mostra o questionário aplicado.

\section{Tabela 2. Questionário aplicado}

\begin{tabular}{|c|c|}
\hline 1 & A dinâmica atendeu as expectativas em relação ao tema proposto: processos. \\
\hline 2 & $\begin{array}{l}\text { Estou satisfeito com a dinâmica apresentada porque foi uma atividade prática diferente } \\
\text { das aulas convencionais. }\end{array}$ \\
\hline 3 & Ao passar pelas etapas da dinâmica senti confiança de que estava aprendendo. \\
\hline 4 & Foi fácil entender a dinâmica e ela pode ser utilizada como material de estudo. \\
\hline 5 & O conteúdo da dinâmica agregou outros conhecimentos que já possuía sobre o tema. \\
\hline 6 & A utilização desta dinâmica está mais adequada ao meu jeito de aprender. \\
\hline 7 & O conteúdo da dinâmica é relevante para entendimento do que é processo. \\
\hline 8 & A utilização de uma dinâmica me fez ficar atento à aula ministrada. \\
\hline 9 & Algo interessante no início da aplicação da dinâmica capturou minha atenção. \\
\hline 10 & $\begin{array}{l}\text { A forma como a dinâmica foi feita é atraente (Apresentação, desenrolar, tarefas, } \\
\text { finalidade). }\end{array}$ \\
\hline 11 & $\begin{array}{l}\text { Tive sentimentos positivos no desenrolar da dinâmica e percebi que é mais eficiente para } \\
\text { o aprendizado. }\end{array}$ \\
\hline 12 & Consegui atingir os objetivos da dinâmica sem maiores dificuldades. \\
\hline 13 & Gostaria novamente de utilizar mais dinâmicas para aprendizado das disciplinas. \\
\hline 14 & Eu recomendaria a aplicação desta dinâmica aos meus colegas. \\
\hline 15 & Me diverti com a dinâmica. \\
\hline 16 & A dinâmica evolui em um ritmo adequado e não fica monótona. \\
\hline 17 & As tarefas envolvidas na dinâmica não são muito fáceis nem muito difíceis. \\
\hline 18 & A dinâmica promove momentos de cooperação entre as pessoas que participam. \\
\hline 19 & Me diverti junto com as outras pessoas do meu grupo. \\
\hline 20 & Foi possível interagir com outras pessoas durante a dinâmica. \\
\hline 21 & Eu não percebi o tempo passar durante a dinâmica e quando vi ela acabou. \\
\hline 22 & $\begin{array}{l}\text { Temporariamente esqueci minhas preocupações do dia a dia. Fiquei totalmente } \\
\text { concentrado na dinâmica. }\end{array}$ \\
\hline 23 & As definições trabalhadas na dinâmica irão contribuir para minha vida profissional. \\
\hline 24 & $\begin{array}{l}\text { A dinâmica foi eficiente para minha aprendizagem em comparação com outras } \\
\text { atividades da disciplina. }\end{array}$ \\
\hline 25 & A dinâmica contribuiu para a minha aprendizagem na disciplina. \\
\hline
\end{tabular}


O questionário teve o objetivo de verificar se, com a aplicação desta dinâmica, o conteúdo foi ensinado de um modo diferente; se foi possível assimilar melhor o conteúdo transmitido em relação ao método tradicional; se os alunos se sentiram motivados a estudar, utilizando artifícios diferentes do método tradicional de ensino. $\mathrm{O}$ universo de alunos da pesquisa realizada consistia em 32 participantes na turma A, 35 participantes na turma B, 25 participantes na turma C. O método utilizado foi de contagem do número de respostas em cada item. Após tratamento e análise dos dados, obteve-se $95 \%$ de sucesso a partir das questões respondidas, que estão entre ter marcado a nota 4 (muito bom) ou 5 (excelente). Alguns itens merecem destaque como é o caso da questão 2 . Cerca de $90 \%$ dos respondentes marcou nota 5, o que leva a concluir que as aulas tradicionais, centradas em conteúdo expositivo, tendem a ser mais enfadonhas. O mesmo ocorreu na questão 13 , com cerca de $91 \%$ dos participantes marcando nota 4 ou 5. Isso também significa que os alunos preferem as atividades lúdicas e, que esse tipo de atividade, possibilita uma melhor absorção do conteúdo trabalhado em sala de aula. A questão 21 , com cerca de $93 \%$ dos participantes marcando nota 5, mostra que os alunos não percebem o passar da aula quando são utilizados recursos lúdicos como recurso para o aprendizado.

Como ponto positivo mais importante da aplicação da dinâmica nas turmas, pode-se destacar a boa aceitação por parte dos participantes de uma outra forma de aprendizado (recursos lúdicos) em relação ao método tradicional (aula expositiva) e, consequentemente, uma maior participação durante a aula. Um ponto negativo observado foi uma certa ociosidade dos membros das equipes gerada na segunda fase da dinâmica, na qual os gerentes poderiam conversar entre si e depois passar as tarefas para suas equipes. Os gerentes ficaram um tempo considerável conversando e não se preocuparam em passar atividades para suas equipes. Em decorrência disso, boa parte da turma ficou ociosa. Os alunos sugeriram uma melhoria na qual os gerentes teriam um tempo estipulado para conversar e, logo após, deveriam passar as tarefas para os membros das equipes.

\section{Conclusão}

O objetivo do artigo foi apresentar uma dinâmica que consiste, através da construção de um boneco por partes, mostrar o ensino de processos e fazer uma analogia ao processo de produção de um software mostrando sua evolução. Além disso, demonstrar que o processo deve sofrer melhorias para que fique cada vez melhor.

Em geral, o método de aprendizado mais aplicado na área educacional é o tradicional com a utilização da forma verbal, que faz uso da escrita ou da fala como meio de comunicação, com avaliações escritas [BEHRENS, 1999]. O uso de recursos lúdicos permite transpor este paradigma e levar o conhecimento de uma forma mais natural e motivadora. Quando é possível realmente atingir um número maior de alunos, sem distorcer o assunto a ser transmitido, percebe-se que o uso do recurso lúdico tem maior eficácia, já que o público fica mais envolvido e participante.

A dinâmica criada teve a intenção que os alunos tivessem uma maior eficácia no processo de ensino e aprendizado. Eles foram convidados a aprender de maneira prática sobre o que é um processo. Além disso, puderam fazer uma analogia com o processo de desenvolvimento de software, sendo motivados a cada etapa. À medida que o projeto se desenvolveu, foram assimiladas noções de trabalho em equipe, a importância da 
documentação, gerência de projetos e requisitos e também a importância do uso de processos na produção de software.

Espera-se também que essa metodologia seja aplicada por outros docentes na área de Engenharia de Software e afins, de forma a motivar os alunos ao aprendizado desta disciplina tão importante.

\section{Referências}

Albuquerque, A. B. (2009) Atividades Lúdicas no Ensino de Processos de Software. VIII Simpósio Brasileiro de Qualidade de Software, Fortaleza, Brasil, 318-325.

Baum, W. M. (1999) Compreender o Behaviorismo Ciência, Comportamento e Cultura (M.T.A. Silva, M.A. Matos, G.Y. Tomanari, E.Z. Tourinho) Porto Alegre.

Behrens, M. A. (1999) O Paradigma Emergente e a Prática Pedagógica. Curitiba: Champagnat.

Davis, R. (2008) ARIS Design Platform: Advanced Process Modelling and Administration. Springer-Verlag, London.

Fernandes, L. \& Werner, C. (2009) Sobre o uso de Jogos Digitais para o Ensino de Engenharia de Software. In: II FEES, SBES, Fortaleza, Brasil, 17-24.

Fernandes, A. A.; Teixeira, D. S. (2011) Fábrica de Software: Implantação e gestão de operações. 1. ed. São Paulo: Atlas.

Filho, P. W.P. (2009) Engenharia de Software: Fundamentos, Métodos e Padrões. 3. ed. Rio de Janeiro: LTC, 1248p.

Júnior, O. S. L.; Farias P. P. M.; Belchior, A. D. (2002). Análise de Pontos por Função Fuzzy. I Simpósio de Qualidade de Software, Gramado, Brasil, 225-236.

Jones C. (2010) Software Engineering Best Practices. McGraw-Hill, Inc., New York, NY, USA, 1 edition.

Matlin, M. W. (2004) Psicologia Cognitiva. LTC.

Piaget, J. (2003) Seis Estudos de Psicologia. 24. ed. Rio de Janeiro: Forense Universitária.

Pressman, R. S. (2011) Engenharia de Software: Uma Abordagem Profissional. 7. ed. São Paulo: McGraw-Hill.

Scheer W.A., Kruppke H., Jost W., Kindermann H. (2006) Agility by ARIS Business Process Management. Berlin: Springer-Verlag.

Wangenheim, C. G. V. (2012) Ensinando Computação com Jogos. 1. ed. São Paulo: Câmara Brasileira do Livro.

Wazlawick, R. S. (2013) Engenharia de Software: Conceitos e Práticas. 368p. Campus. 2013. 